Portland State University

PDXScholar

1975

\title{
Teaching language to hearing impaired children who have had no previous language experience
}

Catherine Collins Lu

Portland State University

Follow this and additional works at: https://pdxscholar.library.pdx.edu/open_access_etds

Let us know how access to this document benefits you.

\section{Recommended Citation}

Lu, Catherine Collins, "Teaching language to hearing impaired children who have had no previous language experience" (1975). Dissertations and Theses. Paper 1330.

https://doi.org/10.15760/etd.1329

This Thesis is brought to you for free and open access. It has been accepted for inclusion in Dissertations and Theses by an authorized administrator of PDXScholar. Please contact us if we can make this document more accessible: pdxscholar@pdx.edu. 
TEACHING LANGUAGE TO HEARING IMPAIRED CHILDREN

WHO HAVE HAD NO PREVIOUS LANGUAGE EXPERIENCE

by

CATHERINE COLLINS LU

A substantial paper submitted in partial fulfillment of the requirements for the degree of

MASTER OF SCIENCE

SPEECH: EMPHASIS SPEECH PATHOLOGY/AUDIOLOGY

Portland State University

1975 


\section{APPROVAL PAGE}

This substantial paper by CATHERINE COLLINS LU was presented on March 11, 1975, and approved by

Joan McMahon 


\section{ACKNOWLEDGEMENTS}

The author wishes to express her personal indebtedness to Joan McMahon for her encouragement and always constructive criticisms during the course of writing this paper. Thanks also go to Dr. Robert Casteel for his suggestion and inspiration in the original choice of this topic and for his many helpful suggestions. 
TABLE OF CONTENTS

PAGE

APPROVAL PAGE ...................

ACKNOWLEDGMENTS ..................... . . . .

CHAPTER

I INTRODUCTION...........................

II A BRIEF HISTORY SINCE 1900 OF LANGUAGE

SYSTEMS . . . . . . . . . . . . . . 4

III GRAMMATICAL SCHOOL . . . . . . . . . . 7

IV DEVELOPMENTAL LANGUAGE INSTRUCTION . . . . . . 9

Rationale..................... 9

Early Amplification ......... 10

Diagnosis

Placement

Hearing Aid Maintenance

Phonology ............. . .

Parent Teacher Coordinated Program . . . .

$\checkmark$ DESCRIPTION OF SOME EDUCATIONAL PROGRAMS

IN PRACTICE . . . . . . . . . . . . . . . . . . 17

VI SUMMARY AND CONCLUSIONS . . . . . . . . . . . . . 22

BIBLIOGRAPHY ..................... 


\section{CHAPTER ।}

\section{INTRODUCTION}

The spontaneous use of language as a means of sending and receiving messages requires the mastery of a very complex set of rules (the grammar). In order to speak and understand effectively, a child must acquire those rules for himself, otherwise he cannot achieve effective communication even with a vast vocabulary available. The difference between vocabulary and language is analogous to that between pharmacology and medicine, where the former deals with the properties of different substances per se, and the latter, the proper combinations thereof to produce the desired effect. For the hearing impaired the difficulty in acquiring grammar is compounded due to the impairment of an important component of communication: hearing.

From the turn of the century until the late fifties, oral deaf education was based on grammatical components. The child was taught single phonemes which were later combined to form new vocabulary words, thus leading to a vocabulary without structural rules (grammar). Language was taught as a separate undertaking. At the onset of the first year of language instruction, the child was taught to speak in sentences by teaching the structural aspects such as that sentences consisted of nouns and verbs, nouns have articles, and verbs have tenses. The hearing impaired child who was denied sufficient opportunity for selfinduced variational development in his language, instead, was led through one specific determined system, such as, the Fitzgerald Key, the Wing Symbols or the Five Slate System. All these systems emphasized 
the use of visible cues to indicate parts of speech and how to use them to form simple language.

The second major school of thought was that of "natural language." Followers of this approach believed that the children's language needs determined the content and sequence of language presentation and that rules and drills should be minimal. Language in this case was inductive for it was learned through exposure and usage in meaningful situations. Schmitt (1970) reported, however, that,

In actuality most classes for the deaf tend to use a "combined" or "eclectic" approaches in which adherence to language outlines, word lists, formal devices, and drills is tempered with childcentered language activities.

Since 1957, linguists began to view language acquisition in a new light. Their studies have provided theories in the receptive and expressive aspects of language. Generative grammar, pertains to the rules concerning the relationship between the semantic and phonetic interpretations of the sentence, or, to put it succinctly, between the meaning and sound (Chompsky, 1966). According to Lehman (1971), "The logical nature of the theory of generative grammar enables the teacher to see the grammar in terms of a developmental sequence." This belief has led to a new direction in language instruction for the hearing impaired child, which will be called the developmental school of thought in this paper. Proponents of the developmental school sometimes refer to the newer trend as the natural approach, but in order to differentiate it from the natural language Groht describes in Natural Language for the Deaf the other name was chosen.

This paper purports to give (1) a systematic review of the background and theoretical development leading to the evolvement of the modern approach of language instruction for the hearing impaired child, 
and (2) a comparison of the grammatical and the developmental schools from the instructional point of view. 
CHAPTER 1 ।

\section{A BRIEF HISTORY SINCE 1900 OF LANGUAGE SYSTEMS}

Since 1900 the main approach to teaching language to hearing impaired children in the U. S. has been grammatical or analytical in nature. In other words, the focus has been upon presenting structural aspects (parts of speech and syntactic rules) to the student. The purpose being that the student would use the rules to structure language deductively. The methods involved formal presentation of the rules and drills.

In 1899 Barry published her Five Slate System and it was widely used in the early 1900's (schmitt, 1970). Her purpose was to present a visible sentence skeleton to the student in which the student could place simple language. The five slates refer to the subject, verb, object of the verb, preposition and object of the preposition. Eventually a sixth slate was added for time and time phrases.

According to Schmitt (1970), numerous books were published which dealt with language development for the hearing impaired child. The following is a brief account of early publications according to Schmitt:

Will loughby wrote Written Exercises on Direct and Indirect Quotations, and in 1915-17 Sweet's First Lessons in Engl ish for the Deaf were revised by people at the American School for the Deaf. It contained language principles and stories using the principles. The Beginner's Book by Upham was published in 1917 and presented developmental lessons involving vocabulary, short sentences and stories. Crocker, Jones and Pratt (1920, 1922, 1928) published four books which included weekly lessons to teach language 
principles. The lessons were cumulative in nature in that a new principle was added but previous ones were reviewed. The lessons consisted of a story, questions to be answered by the student, drills on principles previously presented, practice writing questions and drilis on the new principles.

Fitzgerald's book Straight Language for the Deaf was published in 1926. In it she introduced the Key which consists of six columns. These are designated by interrogative words and symbols that represent parts of speech and sentence functions. She suggests that hearing impaired children be taught by beginning with the basic headings and language be developed by "building the Key." It was to be used as a reference and for self correction purposes for the children.

Buell's book Outline of Language for Deaf Children was publihsed in 1934 and in 1954 the second book was published. They presented Iists of principles, games, exercises and teaching techniques. In 1937 Vinson publ ished Logical System of Language Teaching and an Analysis of the Engl ish Language with a Course of Study in Language. A Manual for Teachers (Schmitt, 1970). It was an extremely detailed analysis of language, an outline of language from the first year to the seventh grade level, a system for teaching language, a key with seven columns, techniques and exercises for practicing the principles.

Central Institute's Language Outline was published in 1950 and included methods for language instruction plus language and vocabulary lists from twenty-six other schools for the hearing impaired, and outlines of Buell, Connery, Davies and Vinson. Pugh (Schmitt, 197.0) published an article in 1955 which described language development based on the Fitzgerald Key and Strent (Schmitt, 1970), in the same year, suggested ideas for teaching language and the development of language through the grades. 
In 1958 Groht's Natural Language for the Deaf advocated a different approach to language. It dealt with "natural approach" rather than the analytic. It was an attempt to teach language the way hearing children acquire it by exposure to correct language patterns and through the child's guided use of language in meaningful situations. The child's needs dictated the vocabulary and language and when principles needed to be taught they were introduced in natural situations, explained in a real situation and practiced by the children through means of stories, pictures, games, questions and conversation. 
CHAPTER 111

GRAMMATICAL SCHOOL

From 1900 to approximately 1958 the approach to teaching language to hearing impaired children was primarily analytical in nature. The children were taught in terms of the structural aspects, i.e., parts of speech and syntactic rules (Schmitt, 1970). The students were expected to use the rules they learned to develop language deductively.

Generally the child's hearing loss was not diagnosed until the age of three or four years of age (Horton, 1968). Little was done aside from the placement of the aid on the child and some advice as to how to get the child accustomed to it.

Once formal education began, usually at the age of four or five, the child's day was divided into blocks of time for speech, auditory training and I ipreading. The speech generally consisted of some voice work, tongue exercises, specific work on individual phonemes, syllable work and, perhaps, some work on breath control. The auditory training included such activities as I istening to gross sounds from devices like a drum, various noise makers and discriminating one from another. The children were also asked to tell whether a sound was present or absent. Lipreading often consisted of the child indicating the correct toy or picture after the teacher said a sentence.

Formal language training was usually begun at the age of six years. It was very structured and the emphasis was on drills and a system such as the Fitzgerald Key, the Barry Five Slates or the Wing 
System was used. The purpose of the system was to provide the child with visible cues to help him correct and/or generate language. By presenting a symbol or an interrogative word to the child (depending on the system) he was to fill in the appropriate word or words. Language was expanded by the continued building of the Key, work on the Barry Five Slates or the Wing Symbols or whatever as the child progressed in school. Speech, auditory training and I ipreading were included along with the academic subjects as the child advanced. Integration with hearing peers in school was usually not recommended until the child was about the eighth grade level.

It was a very rigid and structured approach which seemed to assume that language needed to be programmed into the child item by item. 
CHAPTER IV

\section{DEVELOPMENTAL LANGUAGE INSTRUCTION}

\section{Rationale}

The basic premise of the new method of instruction is based upon the observation that normal children learn their language and speech as an integral part of their growth and development without noticeable difficulty or effort. It is reasoned that the hearing impaired children, other things being equal, would do as well or nearly so if provided with a learning environment closely resembling that of their hearing counterparts. Obviously, the most profound difference in the learning environment of the hearing impaired is the lack of auditory input due to the hearing loss. It is therefore of great importance that the extent of residual hearing be ascertained and the appropriate appliance be adapted as early as possible, preferably before the child is a year old.

Fortunately, most of the so called hearing impaired children are not "stone deaf," but possess some degree of residual hearing which can be brought up to a functional level with proper appliances.

It is also a well known fact that the normal children learn their language and speech in circumstances which are personal and experience oriented. The acquisition of speech seems almost by osmosis, so to speak. It is for this reason that the new approach stresses the importance of experience oriented presentation and parent counselling so the parent knows how to stimulate and respond to the child's auditory experiences. 
As a child grows older, he gains greater control of the oral laryngeal faculty, he is able to begin with simple sounds and proceed to learn the more difficult ones. For example, the sounds of "p" and "m" are usually mastered at about the age of three, whereas the sounds of "sh" and "th" will not be acquired totally until the age of six or seven. The phonological development is a gradual process which is closely related to the neuromuscular development of the child. For this reason, the new method of instruction differs sharply from the traditional one. In the traditional grammatical approach, al I sounds were taught to the hearing impaired children by rote and the children were expected to master them by continuous repetition and drill. The hearing impaired children, handicapped by not having the normal auditory input, were expected to learn the same sounds which their hearing counterparts would learn in time. They were therefore placed in a situation not conductive to learning. Indeed, the forced feeding method could result in irrepairable damage. In view of the above, the new approach insists upon a developmental phonological process closely paralleled to the readiness of the child.

\section{Early Amplification}

According to Fry (1968), a hearing impaired child does go through the vocalizing stage and begins to babble at approximately the same age as the normal hearing child. As time wears on, however, the babbling, as a rule, fades away due to the fact that the child lacks the external auditory stimuli, as well as the auditory stimuli from his own effort. Babbling is important to establish links between the motor activity of speech and auditory feedback. 
Hoffman (1967) reported that listening must be learned by hearing children as well as hearing impaired children and that the learning to Iisten and the ability of auditory discrimination depend to a great degree on the amount of stimulation they receive. She also stated that the sounds must be loud enough, repeated enough and associated with something meaningful to the child in order to be understood. Northcott (1972) stated that hearing aids must be as free of distortion as possible to assure better I istening and the more the child Iistens with his aid, the more the various sounds he perceives will become significant. She also said that children can learn to recognize minimal auditory differences when sufficient practice is combined with prompt reinforcement of appropriate responses. Streng (1967) stated that: "Anything else deprives him of a chance to learn language in a manner which bears at least some semblance to normal language acquisition."

\section{Diagnosis}

The first essential element in the infant program is, of course, early diagnosis. Determination of a hearing loss can be detected at an earlier age in recent years.

If it is suspected than an infant has a hearing loss, Downs (1967) suggests the following steps to determine whether a true peripheral loss does exist and if so, to what extent. The three steps are as follows: (1) Evaluation of the intactness of the central nervous system by a pediatric neurologist; (2) Evaluation of the developmental status of the infant through developmental scales, which although not definitive at this age, can give some prognostic indication; (3) Application of evoked responseaudiometry to indicate definitive thresholds by the age 
of five to six months and collaborative evidence on neurological findings and prospects for use of residual hearing.

Placement

Once a loss is indeed ascertained, the next step is the placement of a hearing aid or aids on the child. Educators advocating the newer trends work closely with audiologists in an effort to provide the child with the most appropriate amplification required by the child's individual needs.

The types of aid or aids vary according to the program. In many programs such as the Bill Wilkerson Hearing and Speech Center and the HEAR Foundation binaural aids are recommended. Griffiths stated (1967) that sound supplied by binaural aids gives the child a sense of localization of sound stimuli and improved quality for some hair cells which cannot be tested on the audiometer may be stimulated. This appears to be a growing trend, but in other programs single aids are still used.

In the past, diagnosis of a hearing loss was considered early at the age of three or four years, and even if the child obtained an aid (Horton, 1968), Lenneberg (1967) stated that serious sound training did not begin until the age of three or four years or even later. It is apparent that there is a great deal of difference between traditional and new approaches to the auditory sense for auditory training now is begun as soon as the aid has been placed on the child. Much more importance is being placed on auditory training today. Those advocating the new trends firmly believe that early and proper amplification will complete the child's auditory feedback loop thus enabling the child to pass through the babbling stage and continue on the road to normal language development. 
Hearing Aid Ma intenance

All the programs of early amplification constantly re-evaluate the aid or aids to insure that the child receives maximum benefit for his impairment. Horton (1968) stated that audiologic assessment must be a continuing, integral part of the total program. Therefore audiologists are a very important part of the programs.

Since amplification is felt to be such an important part of the program, parents, therapists, hearing aid dealers and audiologists must work together to keep the aids in top working condition (Northcott, 1972). Parents should be taught how to make daily minor adjustments on the aids. Therapists should check aids each time the child is seen and the aids should be checked by an audiologist frequently. Hearing aid dealers must provide quick reliable service.

\section{Phonology}

Phonology is the sound or vocal system of the language. It includes phonemes and prosody (Simmons, 1968). The phonemes are the most stable unit in language because there are appproximately 46 of them and are combined to form morphemes of the Engl ish Ianguage. Prosody is the overall musical pattern of the language, phonation and duration which children with very profound hearing losses can detect (Silverman, 1949). Intonation does not carry meaning alone, however, the phonemes must be intellegible so the listner can discriminate sounds within words (Simmons, 1970).

Simmons (1970) suggested that perhaps in the past hearing impaired children had unpleasant, irrhythmic voices was due to the overemphasis on breath exercises and individual phoneme practice, rather than on natural, connected language. Since the hearing child goes through the jargon stage before others become concerned about his articulation, it 
seems reasonable that the hearing impaired child should also be allowed to do the same. It is this belief that the newer trends seem to follow in approaching speech; to allow the child to go through the developmental stages until he is using kernel sentences before articulatory work is done. In that way, intonation, duration and phonation are established naturally. Fry (1966), Griffith (1967) and Simmons (1970) reported that the children had more natural voices and rhythm in spite of severe hearing losses.

\section{$\underline{\text { Parent }}$ Teacher $\underline{\text { Coordinated Program }}$}

McNeil stated:

Grammatical speech does not begin before one and one-half years of age; yet as far as we can tell, the basic process is complete by three onad one-half years. Thus a basis for the rich and intricate competence of adult grammar must emerge in that short span of twenty-four months.

That "basic process" according to Chompsky (1971) is the generation of a set of rules which constitute the grammar of the child's language. All this assumes, however, that the child has normal hearing, but a hearing impaired child is denied the most important source of language input. Therefore, early amplification is of great importance as stated in the previous chapter.

Both hearing and hearing impaired children need more than just auditory input to make language meaningful. In studying language of children with two, three or four word utterances, it was found by Brown, Ervin and Braine to follow certain simple patterns (MCNeil, 1966). It seems reasonable to assume that since children go through the process of progression of grammar, a hearing impaired child should also go through the process.

How can all this take place with a hearing impaired child? Certainly 
early amplification is not enough. Likewise weekly sessions or even daily sessions with a clinician are not sufficient for auditory input leading to the command of the English language. It seems logical then that the parents be trained to work with their child since they are the principal figures in their child's life and spend more time with him than anyone else. Therefore, parental training becomes of paramount importance. Simmons (1968a) reported that psychologists have pointed out that in regard to children's learning that the more exposure the child has to sight and sound and is helped to interpret, the more likely he will want to see and hear and he will get more from the senses and will want to share.

Parental training according to Simmons, Horton, and Northcott and Griffiths, is to capitalize on the parents' natural way of stimulating and responding to a child and to maximize the auditory input and experience of the child. The educators mentioned above feel that the parents need to know how to check hearing aids to keep them in good working order, but they must also know how to talk to their child and focus attention on auditory stimuli. Horton (1968) said, "The approach to language learning is largely natural. Reception rather than expression of language is stressed. Emphasis on expression focuses on connected verbalization including pitch variation."

Northcott (1972) said after discussing the parent teaching program, "Such a program offers a firm foundation for the development of connective language and utilization of residual hearing by the child in setting of varying learn-by-doing situations."

Griffiths (1967) reported that parents are requested to talk about objects given to the child to play with or are presented to the child as 
he is being cared for, i.e., a rattle, or a bottle, talking as they would to a hearing child. They are also requested to repeat a sound, if it is possible, if the child turns to it.

The emphasis for parental training is on auditory experience, talking to the child as if he heard giving him extensive auditory input attaching meaning to sounds by demonstrating and explaining them so it is experience oriented. 


\section{CHAPTER V}

\section{DESCRIPTION OF SOME EDUCATIONAL PROGRAMS IN PRACTICE}

During the past fifteen years a significant change has taken place in the emphases and approaches in the education of hearing impaired children. Four of the most significant approaches now in use are: the Acoupedics, Griffith, Grammatico and Auditory/Oral.

The Acoupedics approach as advocated by Pollack (1964) is that auditory training is the most important factor in language development. She suggested Acoupedics as the name for the new program based upon the premise that if all the emphasis is placed upon training audition first, hearing can be integrated into the personality of the young deaf child and a fundamental part of speech and language can be learned through the auditory pathway. For that reason, she has worked with the health profession and established a sophisticated program for early detection of hearing impairment in infants. Once the hearing loss is ascertained, the expertise of various disciplines such as occupational therapist, psychologists, teachers of the deaf, etc., were also enlisted.

The three basic principles of her approach are as follows: "(1) All basic emphasis in early training is upon audition. (2) Avoidance of lipreading and other visual cues. (3) Use of normal speech patterns." In addition she works closely with parents of the children to emphasize the importance of audition in their child's life.

She divides the development of auditory function into the following levels with expected receptive and expressive language in each: "(1) the 
vocal level, (2) the verbal level, (3) the syntactic level, and (4) the pre-educational to educational level." She takes the children through the above levels using only auditory skills.

Griffiths (1967) of the HEAR Foundation stated that the hearing impairment must be diagnosed as early as possible and binaural hearing aids must be placed on the child as soon as the impairment is established. She trained parents to keep the aids in good working order by checking them each day for volume and clarity. Parents were told to talk to their child as if he were hearing and formal training is begun once he has hearing aids. She claimed to have been able to achieve her goal of integration by the time the children are five or six years old. Her exact techniques, however, have not been published. She claimed that the auditory abilities developed by the use of the techniques were: (1) a listening attitude, (2) attention and response to auditory patterns, (3) identification of auditory patterns, (4) repetition of auditory patterns, (6) spontaneous speech stimulated through recognition of auditory cues. Griffiths (1964) stated that Iipreading is allowed in the program although not taught per se.

Grammatico of the Peninsula Oral School, follows the curriculum design of Hilda Taba. Taba's (Grammatico, 1974) strategies for teaching three cognitive tasks leading to abstract thinking are: (1) concept formation, (2) interpretation, and (3) application of principles. Grammatico ascribes to this particular program because she felt it best suited to the development of communication skills, i.e., listening, language, speech and cognition. It is the emphasis on the latter in which her program differs from the others. She Stated:

On the preschool level our behavioral objectives include the 
child's developing listening skills, watching, imitating, using language spontaneously, developing concepts, making comparisons, inferring, expressing feelings (his own and others), thinking independently and producing correct speech sounds (Grammatico, 1974).

The language taught is based upon the child's surroundings and experiences, since hearing children hear the same language repeatedly before they spontaneously use it. The staff at the school try to exercise some control of the language. However, language is not controlled in the sense of lists of nouns, verbs, etc., but is determined by the curriculum content which is coordinated with the child's learning experiences.

The Auditory/Oral approach is used by Horton (1968), Northcott (1972) and Simmons (1972). This approach is used to guide the children through the normal stages of language development with particular emphasis on auditory training. It differs from Pollack's (1964) in that audition is not the only stimulus, but vision also plays an important role. The approach is an experience oriented one not only at school but at home also. Northcott (1972) and Horton (1968) stated that one of the principal goals was to develop the way in which parents should stimulate and respond to their child and to emphasize auditory stimuli so the child will have a stimulating learning environment at home.

Northcott (1972) reported the main objectives for the child to be:

1. Development of reliance upon receptive and expressive language as a normal means of communication.

2. Enrichment of auditory experience to ensure optimum use of residual hearing.

3. Spontaneous ability to use voice purposively in communication, monitoring its volume despite imperfect speech and immature language patterns.

4. Increased maturity to a level compatible with the child's age and stage of development.

The following is a general overview of the education of the young 
hearing impaired child in the developmental school:

All the educators previously discussed agree that a hearing child receives constant auditory input from his environment, the people around him and particularly from his mother. Pollack (1964) said that usually mothers talk to their children continuously during their waking hours and that the vocalization does not necessarily end when the mothers leave the room, for often, they call to their child when out of sight. He feels that language is taught to the child by inundating him with words, phrases, sentences. This inundation and continuous repetition teaches him the patterns of the language with which he is surrounded. The experience of vocalization accompanied by actions of the mother makes the intonation, words and phrases meaningful to the child.

Due to this philosophy, the developmental infant programs (ages 0-3 years) are tutorial in nature. The purpose of this is to provide parents maximum help with problems or questions and for demonstration experiences. Horton (1968) and Simmons (1968a) prefer using a homelike situation with children of this age. In this setting the parents can do routine home activities such as making the bed or vacuuming the rug with the child while the clinician provides information on the type of language which should be presented to the child, how to expand the child's language and how to do the activity to provide stimulating auditory experiences. Grammatico and Pollack feel, however, that the necessary help can be given to the parents in a clinical setting.

At the age of three years nursery school with hearing peers is encouraged by the developmental educators. They feel this integration provides valuable listening experiences to children whose age and interests are those of his own. It also provides the presentation of language 
in child centered activities so the child takes part in the activity as he receives the language to describe it. Therefore, he starts to reason and conceptualize. Auditory stimuli around him encourages him to use his residual hearing and to use his hearing aid more effectively. The child is also motivated to use oral expression because his peers are using it. In addition to the above, special education for his hearing impairment may be tutorial or in classes depending on the facilities of the various centers. Experience oriented activities are the basis of all the programs. Simmons (1968b) stated that teachers of the hearing impaired, at this point, are primarily concerned with developing language so the children will later be able to handle elementary textbooks. She also reported that language and curriculum are interrelated. Content subjects should be the source of vocabulary, syntax and speech patterns and presentation should be in the form of first hand experiences. (A variety of situations help the learning of the concept, and the language to express it and the comprehension of it.)

The developmental educators agree that the children should be integrated into hearing classrooms as soon as they can handle the language and academic material. Maintainance is done in tutorial sessions until the child is able to continue without special help. 


\section{CHAPTER VI}

\section{SUMMARY AND CONCLUSIONS}

The following is a brief review and analysis of what has been previously discussed:

The philosophy of the grammatical school of thought is that language must be taught from without by carefully structured presentations of language principles arranged in a "logical" sequence. It is believed that as the children acquire the language principles they will be able to develop language deductively.

On the other hand, developmental language approach holds that the capacity for language is innate and can be nurtured to higher development. It is also believed that language is entwined with speech and the two are inseparable.

For infants (ages $0-3$ ) the grammatical approach offers very little except diagnosis of the loss, the placement of a hearing aid, and perhaps some structured work on vocabulary. In the developmental approach, in addition to diagnoses and receiving aids, the parents are recruited into the program as a part of the education, i.e., they are (1) counselled as to how to stimulate vocal responses from the child, (2) how to respond to the child to provide him with good language modes, and (3) how to capitalize on auditory stimuli to get the child to make use of his residual hearing.

At the preschool age the child in the grammatical program experiences specific speech work on the phonemes, vocabulary building exercises, 
speech reading, and auditory training. The child in the developmental approach is being tutored or is in class working on language with associated activities. The auditory training and speech reading (if used) are purposely built into the activities. The child is being taught through experience.

The primary level the child in the grammatical approach continues the previous work but language is also begun in a structured way. The child in the developmental approach continues to learn through activities and speech is begun once the child is using kernel sentences spontaneously.

In comparing these two approaches, it appears the child in the developmental approach is more likely to communicate effectively with others than the ones in the grammatical approach, because of a head start on language. To that child, language is meaningful and he has had opportunities to experiment with it and use it. People have responded to him and he has realized it to be manipulative. It is analogous to someone moving to a foreign country at a young age. The child learns the language quickly because he is surrounded by it, hears it everywhere and adapts to it. He uses what he knows and constantly builds, refines, and improves upon it until he is able to communicate effortlessly. On the other hand, the teaching of the language principles is similar to the teaching of a foreign language beginning with phonemes and grammar. Experience has shown that even when one is familiar with the phonemes and the correct principles, communication is still constrained due to lack of practice. Furthermore emphasis on auditory stimuli may enable the child to make better use of his residual hearing. 
speech reading, and auditory training. The child in the developmental approach is being tutored or is in class working on language with associated activities. The auditory training and speech reading (if used) are purposely built into the activities. The child is being taught through experience.

The primary level the child in the grammatical approach continues the previous work but language is also begun in a structured way. The child in the developmental approach continues to learn through activities and speech is begun once the child is using kernel sentences spontaneously.

In comparing these two approaches, it appears the child in the developmental approach is more likely to communicate effectively with others than the ones in the grammatical approach, because of a head start on language. To that child, language is meaningful and he has had opportunities to experiment with it and use it. People have responded to him and he has realized it to be manipulative. It is analogous to someone moving to a foreign country at a young age. The child learns the language quickly because he is surrounded by it, hears it everywhere and adapts to it. He uses what he knows and constantly builds, refines, and improves upon it until he is able to communicate effortlessly. On the other hand, the teaching of the language principles is similar to the teaching of a foreign language beginning with phonemes and grammar. Experience has shown that even when one is familiar with the phonemes and the correct principles, communication is still constrained due to lack of practice. Furthermore emphasis on auditory stimuli may enable the child to make better use of his residual hearing. 
Although the above conclusions appear to be logical, there is no experimental proof at this time to support them. This seems to be an area in which research would contribute a great deal to education for the hearing impaired child. 


\section{BIBLIOGRAPHY}

Aurbsch, Joseph, Philip H. Cook, Robert B. Kaplan and Virginia Tufte. Transformational Grammar: A Guide for Teachers, Washington Educational Associates, Inc., 1969, pp. 3-4.

BuelI, E. M. Outline of Language for Deaf Children, Book I and Revised Book II. Washington, D. C.: The Volta Bureau (1934, 1954).

Central Institute for the Deaf (Teacher Committee). "Language OutIine," American Annals of the Deaf, 95, 353-378 (1950).

Crocker, G. W., Jones, M.K. and Prat, M.E. Language Stories and Drills. Books I, II, III and IV. Battleboro, Vermont: Vermont Printing Co. $(1920,1922,1928)$.

Chomsky, Carol. The Acquisition of Syntax in Children from $\underline{5}$ to 10 , Cambridge: M.I.T. Press, (1971).

Downs, Marion. "Early Identification and Principles of Management," Proceedings International Conference for Oral Educators of the Deaf, Vol. I, 746-757 (1967).

Fitzgerald, Edith. Straight Language for the Deaf, Staunton, Virginia: The McClure Company, Inc. (1926); Washington, D.C.: The Volta Bureau (1949).

Fry, D. B. The Genesis of Language A Psychol inguistic Approach, ed. by Frank Smith and George A. Miller, Cambridge: M.I.T. Press, 187-206, (1966).

Grammatico, Leahea. "Building a Language Foundation at the Preschool Level," Volta Review, Vol. 66, No. 7, 378-382 (Sept. 1964).

Grammatico, Leahea and Sophia Dhimitri Miller. "Curriculum for the Preschool Deaf Child," Volta Review, Vol. 76, No. 5 280-289 (May 1974).

Griffiths, Ciwa. "The auditory Approach for Preschool Deaf Children," Volta Review, Vol. 66, No. 7, 387-396 (Sept. 1964).

Groht, Mildred A. Natural Language for Deaf Children, Washington, D.C. : Alexander Graham Bell Association for the Deaf, Inc. (1958).

Hoffman, Grete. "Adjustment and Communication by Maximum Use of Residual Hearing," Proceedings International Conference for Oral Educators of the Deaf, Vol. I, 733-745 (1967). 
Horton, Kathryn. "Home Demonstration Teaching for Parents of Very Young Deaf Children," Volta Review, Vol. 70, No. 2, 97-101 (Feb. 1968).

Hopper, Robert and Rita C. Naremore. Children's Speech, New York: Harper \& Row Publishers, Chap. 4, (1973), Development of Syntax: What Really happened Behind the Transformational Tree.

Lenneberg, Eric H. Biological Foundations of Language, New York: John Wiley \& Sons, Inc. (1967).

Liversidge, Ellen M.A. and Gregory M. Grana, M. Div. "A Hearing Impaired Child in the Family: A Parent's Perspective, Volta Review, Vol. 75, No. 3, 174-185 (March 1973).

Northcott, Winifred. Speech for the Deaf Child: Knowledge and Use, Leo E. Connor, Editor, Washington, D.C.: Alexander Graham BelI Association for the Deaf, 311-331 (1971).

McNei I, David. "The Capacity for Language Acquisition," Volta Review, Vol. $68,17-33$ (1966).

Pollack, Doreen. "Acoupedics: A Uni-Sensory Approach to Auditory Training," Volta Review, Vol. 66, No. 7 400-409 (Sept. 1964).

Pollack, Doreen. "The Development of an Auditory Function," 1970 Handout at the Regional A.O.H.E. I Meeting, October, 1973.

Schmitt, Philip J. "Language Instruction for the Deaf," Selected Readings in Language for Teacher of the Hearing Impaired, Jean Lehman, Ed. New York: Simon and Schuster, (1970).

Silverman, S. Richard. "The Implications for Schools for the Deaf of Recent Research on Hearing Aids," American Annals of the Deaf, Vol. 94, 325-339, (1949).

Simmons, Audrey Ann, Ed. D. "Teaching Aural Language," Volta Review, Vo. 70 No. 1, 26-30 (Jan. 1968 (a)).

Simmons, A. A. "Content Subjects Through Language," Volta Review, Vol. 70, No. 6 481-486 (Sept. 1968 (b))

Simmons, Audrey A. "Motivating Language in the Young Deaf Child," Selected Readings in Language for Teachers of the Hearing Impaired, Jean Lehman, Ed., New York: Simon \& Schuster, (1970).

Simmons-Martin, Audrey A. "The Oral/Aural Procedure: Theoretical Basis and Rationale," Volta Review, Vol. 74, No. 9, 541-551 (Dec. 1972).

Streng, Alice H. "The Language Arts in the Curriculum for Deaf Children," Volta Review, Vol. 70, No. 6, 487-492 (Sept. 1968).

Streng, Alice H. Syntax, Speech and Hearing Applied Linguistics for Teachers of Children with Language Hearing Disabilities, New York: Grune \& Stratton, (1972).

Van Uden, Anthony. "New Realizations in the Light of the Pure Oral Method," Volta Review, Vol. 72, No. 9, 524-536 (Dec. 1970). 
Woodward, Helen. "The Social Studies in a School for Deaf Children," Volta Review, Vol. 70, No. 6, 405-409 (Sept. 1968). 